\title{
Docosahexaenoic acid liposomes for targeting chronic inflammatory diseases and cancer: an in vitro assessment
}

This article was published in the following Dove Press journal:

International Journal of Nanomedicine

5 October 2016

Number of times this article has been viewed

\author{
Amr Alaarg ${ }^{1,2}$ \\ Nan Yeun Jordan' \\ Johan JF Verhoef' \\ Josbert M Metselaar ${ }^{2,3}$ \\ Gert Storm ${ }^{1,2}$ \\ Robbert J Kok' \\ 'Department of Pharmaceutics, \\ Utrecht Institute for Pharmaceutical \\ Sciences, Utrecht University, Utrecht, \\ ${ }^{2}$ Department of Biomaterials \\ Science and Technology, Institute for \\ Biomedical Technology and Technical \\ Medicine (MIRA), University of \\ Twente, Enschede, the Netherlands; \\ ${ }^{3}$ Department of Experimental \\ Molecular Imaging, University \\ Clinic and Helmholtz Institute for \\ Biomedical Engineering, RWTH- \\ Aachen University, Aachen, Germany
}

Correspondence: Robbert J Kok Department of Pharmaceutics, Utrecht Institute for Pharmaceutical Sciences, Utrecht University, Universiteitsweg 99, 3584 CG Utrecht, the Netherlands

$\mathrm{Tel}+3$ I 620275995

Fax +3। $3025 \mid 789$

Email r.j.kok@uu.nl

\begin{abstract}
Inflammation, oxidative stress, and uncontrolled cell proliferation are common key features of chronic inflammatory diseases, such as atherosclerosis and cancer. $\omega 3$ polyunsaturated fatty acids (PUFAs; also known as omega3 fatty acids or fish oil) have beneficial effects against inflammation upon dietary consumption. However, these effects cannot be fully exploited unless diets are enriched with high concentrations of fish oil supplements over long periods of time. Here, a nanomedicine-based approach is presented for delivering effective levels of PUFAs to inflammatory cells. Nanoparticles are internalized by immune cells, and hence can adequately deliver bioactive lipids into these target cells. The $\omega 3$ FA docosahexaenoic acid was formulated into liposomes ( $\omega$-liposomes), and evaluated for anti-inflammatory effects in different types of immune cells. $\omega$-Liposomes strongly inhibited the release of reactive oxygen species and reactive nitrogen species from human neutrophils and murine macrophages, and also inhibited the production of the proinflammatory cytokines TNF $\alpha$ and MCP1. Moreover, $\omega$-liposomes inhibited tumor-cell proliferation when evaluated in FaDu head and neck squamous carcinoma and $4 \mathrm{~T} 1$ breast cancer cells in in vitro cultures. We propose that $\omega$-liposomes are a promising nanonutraceutical formulation for intravenous delivery of fish oil FAs, which may be beneficial in the treatment of inflammatory disorders and cancer.
\end{abstract}

Keywords: nanomedicine, PUFA, inflammation, cancer, fish oil, delivery

\section{Introduction}

Dietary $\omega 3$ polyunsaturated fatty acids (PUFAs), including docosahexaenoic acid (DHA), have been reported to be beneficial in the treatment of cardiovascular diseases and cancer. ${ }^{1-4}$ Such diseases share common pathophysiological features, including unbalanced oxidative stress, an inflammatory microenvironment, and aberrant cell proliferation, which are potential therapeutic targets for PUFAs. ${ }^{5-9}$ Several clinical studies have been conducted to exploit the beneficial effects of PUFAs. However, such effects on the aforementioned targets are typically observed after long-term oral consumption of PUFAs in high amounts. ${ }^{10,11}$ The oral dosage of DHA intake varies, ranging from 0.4 to $4 \mathrm{~g}$ /day for at least 4 months (NCT01078909 and NCT01865448). Bouwens et al used a combination of DHA and eicosapentaenoic acid (EPA; $1.8 \mathrm{~g} /$ day for 26 weeks) to demonstrate anti-inflammatory effects in humans. ${ }^{12}$

To benefit fully from the effects of PUFAs, we propose a novel approach to enrich their content specifically in target cells that are involved in inflammatory disorders. Instead of oral intake of high doses of fish oil, we propose to specifically increase the levels of PUFAs in inflamed lesions through the use of nanomedicine. Nanoparticles can accumulate in inflamed tissues and are efficiently taken up, mainly 


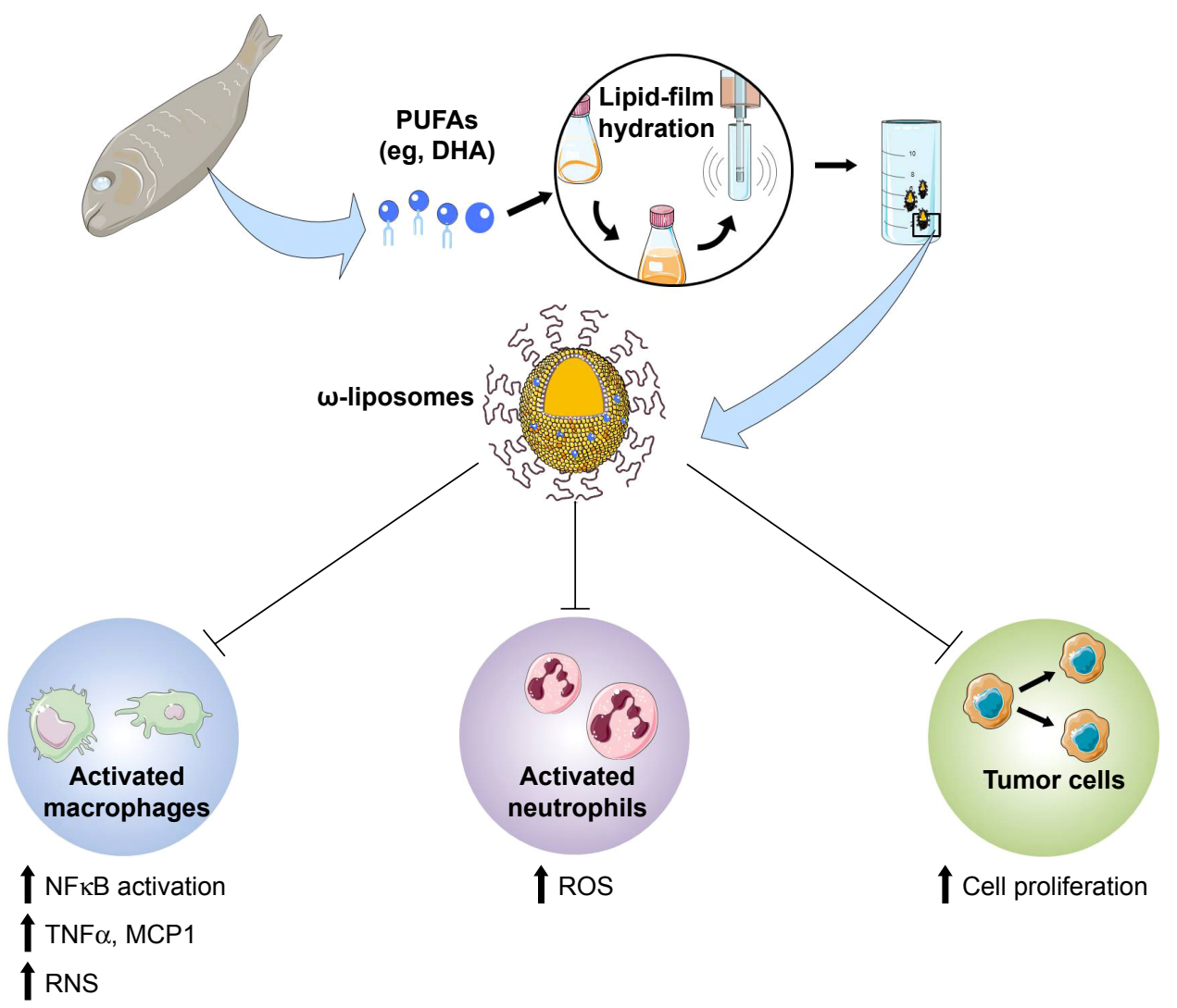

Figure I Preparation of $\omega$-liposomes and their cellular targets in disease.

Notes: Fish oil and oily fish are rich in $\omega 3$ polyunsaturated fatty acids (PUFAs) such as docosahexaenoic acid (DHA). We formulated DHA into $\omega$-liposomes by lipid-film hydration followed by downsizing using extrusion. PEGylated long-circulating liposomes have been shown to accumulate in inflammatory lesions and tumors via the enhanced retention and permeability effect, and thus facilitate local delivery of the PUFAs in $\omega$-liposomes. Multiple pathophysiological processes can be tackled with $\omega$-liposomes. Tissue-associated immune cells, such as plaque macrophages or tumor-associated macrophages, accelerate the progression and invasiveness of the disease by releasing proinflammatory cytokines, such as TNF $\alpha$ and MCPI, and reactive nitrogen species (RNS), which are usually mediated by increased activity of NFKB. Neutrophils can also have significant effects on destabilizing atherosclerotic plaques or on tumor progression via the release of reactive oxygen species (ROS) and via intercommunication with macrophages. A third target for $\omega$-liposomes is the abnormal cellular proliferation of tumor cells.

Abbreviations: PEG, polyethylene glycol; $\omega$-liposomes, docosahexaenoic acid-loaded liposomes.

by macrophages and to a lesser extent other immune cells. ${ }^{13}$ The accumulation of nanoparticles in pathological tissues was first described for tumors and occurs via their enhanced extravasation through leaky blood-vessel walls. ${ }^{14}$ This phenomenon has been named the enhanced permeability and retention (EPR) effect and has also been described for chronic inflammatory disorders, such as rheumatoid arthritis and atherosclerosis. ${ }^{15,16}$ An example of a clinically available nanomedicine that exploits the EPR effect is the liposomal formulation of doxorubicin, branded Doxil, indicated for breast cancer, ovarian cancer, multiple myeloma, and AIDSrelated Kaposi's sarcoma. ${ }^{17,18}$

We propose a novel liposomal formulation of docosahexaenoic acid-loaded liposomes ( $\omega$-liposomes), by incorporating DHA into polyethylene glycol (PEG) ylated liposomes. Such long-circulating PEGylated liposomes can accumulate in inflamed tissues and deliver their PUFA cargo into macrophages and other immune cells. In the present study, we report the physicochemical characteristics of $\omega$-liposomes and their anti-inflammatory effects in different types of immune cells (Figure 1). In addition, to demonstrate their potential benefit in the treatment of cancer, their growth-arresting effects in human and murine cancer cell lines were also evaluated.

\section{Materials and methods Chemicals}

1,2-Dipalmitoyl-sn-glycero-3-phosphocholine (DPPC) and $N$-(carbonyl-methoxy-PEG $\left.{ }_{2,000}\right)$-1,2-distearoyl-snglycero-3-phosphoethanolamine (DSPE-PEG ${ }_{2,000}$ ) were purchased from Lipoid AG (Steinhausen, Switzerland). L- $\alpha$-Phosphatidylethanolamine- $N$-(lissamine rhodamine B sulfonyl) (rhodamine PE) was obtained from Avanti Polar Lipids (Alabaster, AL, USA). All other materials were purchased from Sigma-Aldrich Co. (St Louis, MO, USA) unless otherwise stated. 


\section{Liposomal preparation and DHA loading into liposomes}

DHA-loaded liposomes ( $\omega$-liposomes) and control liposomes (C-liposomes) were prepared with DPPC, cholesterol, DSPE-PEG $_{2,000}$, and DHA ( $\omega$-liposomes only) in molar ratios indicated in Table 1. Rhodamine PE was added at $0.2 \mathrm{~mol} \%$ for fluorescent labeling when applicable. Typical batch sizes were prepared with $20 \mathrm{mM}$ total lipid (TL). Liposomes were prepared using lipid film/hydration. Lipids, including DHA, were dissolved in chloroform-methanol $(1: 1 \mathrm{v} / \mathrm{v}$, total $4 \mathrm{~mL})$ in a round-bottom flask, and a lipid film was prepared by rotary evaporation (Büchi Labortechnik AG, Flawil, Switzerland), followed by an additional drying step under a stream of nitrogen for 1 hour. Subsequently, the lipid film was hydrated with $5 \mathrm{~mL}$ 4-(2-hydroxyethyl)1-piperazineethanesulfonic acid (HEPES)-buffered saline (HBS) solution ( $\mathrm{pH}$ 7.4) to form a lipid dispersion. To downsize the lipid dispersion and to form uniform-size liposomes, the lipid particles were reduced by multiple sequential extrusion steps using a Lipex extruder (Northern Lipids, Burnaby, BC, Canada) through polycarbonate membranes (Nuclepore, Pleasanton, CA, USA) with final filters of pore size $100 \mathrm{~nm}$. The resulting liposomes were purified by either sequential centrifugation steps (as per Eckert et al) ${ }^{19}$ or by ultrafiltration. Briefly, liposomes were centrifuged at $8,000 \times g$ for 20 minutes to remove the debris. The supernatant was removed and centrifuged again at $15,000 \times \mathrm{g}$ for 20 minutes or subjected to ultrafiltration using filtration units with a $100 \mathrm{kDa}$ molecular weight cutoff (Sartorius Stedim Biotech SA, Aubagne, France). Liposomes were then filtered through a $0.22 \mu$ m nylon filter (CellTreat Scientific Products, Pepperell, MA, USA).

\section{Characterization of liposomes}

The mean particle-size distribution and polydispersity index (PDI) of the liposomes were determined by dynamic light scattering (DLS) using a Malvern CGS-3 multiangle goniometer (Malvern Instruments, Malvern, UK) with a
JDS Uniphase $22 \mathrm{~mW} \mathrm{He}-\mathrm{Ne}$ laser operating at $632 \mathrm{~nm}$, an optical fiber-based detector and a digital LV/LSE-5003 correlator. All measurements were performed at a $90^{\circ}$ angle. The $\zeta$-potential of the liposomes was determined by laser Doppler electrophoresis using a Zetasizer Nano-Z (Malvern Instruments). Liposomes were diluted in $10 \mathrm{mM}$ HEPES buffer ( $\mathrm{pH}$ 7.4) prior to measurements. The phospholipid content of liposomes was determined with a phosphate assay, in accordance with Rouser et al. ${ }^{20}$ The DHA content of liposomes was determined after their disruption in acetonitrile by high-performance liquid chromatography on a Shimadzu system equipped with a C18 column, two LC-10AT pumps, and an SPD-M10AVP photodiode array detector at a wavelength of $237 \mathrm{~nm}$. The absence of free DHA and the homogeneity of particle size were confirmed by separation of free DHA from liposomes by size-exclusion chromatography on a Superdex 10/300 column (GE Healthcare UK Ltd, Little Chalfont, UK) using phosphate-buffered saline as eluent at a flow rate of $1 \mathrm{~mL} / \mathrm{min}$. Liposome colloidal stability under storage conditions was studied by monitoring their mean size and size distribution with DLS every 4-5 days for 30 days upon storage in $\mathrm{HBS}$ at $4^{\circ} \mathrm{C}$.

\section{Experiments with immune cells}

Murine RAW264.7 macrophages and human THP1 monocytes were obtained from the American Type Culture Collection (ATCC). RAW264.7 macrophages were cultured in Dulbecco's Modified Eagle's Medium (DMEM) high glucose, while THP1 cells were cultured in Roswell Park Memorial Institute 1640 medium. Both media were supplemented with $10 \%(\mathrm{v} / \mathrm{v})$ fetal bovine serum, penicillin $(100 \mathrm{IU} / \mathrm{mL})$, streptomycin $(100 \mu \mathrm{g} / \mathrm{mL})$, and amphotericin B $(0.25 \mu \mathrm{g} / \mathrm{mL})$ and incubated at $37^{\circ} \mathrm{C}$ under $5 \% \mathrm{CO}_{2}$ atmosphere. THP 1 monocytes were differentiated into macrophages by stimulation with $50 \mathrm{ng} / \mathrm{mL}$ of phorbol-12myristate-13-acetate (PMA) for 24 hours. Afterward, PMA was washed and cells incubated in fresh medium for another 24 hours. The RAW264.7 NFkB Luc-reporter cell line,

Table I Characteristics of liposomes

\begin{tabular}{|c|c|c|c|c|c|c|c|}
\hline $\begin{array}{l}\text { Liposomal } \\
\text { formulation }\end{array}$ & $\begin{array}{l}\text { Molar ratio } \\
\text { (DHA:DPPC:Chol: } \\
\text { DSPE-PEG }_{2,000} \text { ) }\end{array}$ & $\begin{array}{l}\text { Mean } \\
\text { diameter } \\
(\mathrm{nm})\end{array}$ & $\begin{array}{l}\text { Polydispersity } \\
\text { index }\end{array}$ & $\begin{array}{l}\zeta \text {-Potential } \\
(\mathrm{mV})\end{array}$ & $\begin{array}{l}\text { Total } \\
\text { lipid } \\
\text { yield (\%) }\end{array}$ & $\begin{array}{l}\text { DHA- } \\
\text { loading } \\
\text { content (\%) }\end{array}$ & $\begin{array}{l}\text { DHA- } \\
\text { entrapment } \\
\text { efficiency (\%) }\end{array}$ \\
\hline$\omega$-liposomes & $\mathrm{I}: 0.85: 1: 0.15$ & $99 \pm 16$ & $0.06 \pm 0.01$ & $-15.7 \pm 2.5$ & $69 \pm 8$ & $14.6 \pm 1.2$ & $81.35 \pm 3.24$ \\
\hline C-liposomes & $0: 1.85: 1: 0.15$ & $100 \pm 17$ & $0.08 \pm 0.03$ & $-15.0 \pm 0.6$ & $70 \pm 10$ & Not applicable & Not applicable \\
\hline
\end{tabular}

Notes: Data presented as ratio or mean \pm SD $(n=3)$.

$\begin{gathered}\text { Total lipid } \\ \text { yield }(\%)\end{gathered}=\frac{\text { Total lipid recovered }(\mu \mathrm{mol})}{\text { Initial lipid used }(\mu \mathrm{mol})} \times 100 \%, \begin{gathered}\text { Entrapment } \\ \text { efficiency }(\%)\end{gathered}=\frac{\text { Final drug/lipid ratio }}{\text { Initial drug/lipid ratio }} \times 100 \%, \quad \begin{gathered}\text { Loading } \\ \text { content }(\%)\end{gathered}=\frac{\text { Amount of DHA }(\mathrm{mg})}{\text { Amount of total lipid }(\mathrm{mg})} \times 100 \%$.

Abbreviations: DHA, docosahexaenoic acid; DPPC, I,2-dipalmitoyl-sn-glycero-3-phosphocholine; Chol, cholesterol; DSPE, distearoyl phosphatidylethanolamine; PEG, polyethylene glycol; $\omega$-liposomes, docosahexaenoic acid-loaded liposomes. 
stably transfected with 3x-NFKB Luc plasmid, was kindly provided by Professor MPJ de Winther (Academic Medical Centre, Amsterdam), and cultured as RAW264.7 cells. Human polymorphonuclear neutrophils (PMNs) were freshly isolated from a human buffy coat (Sanquin Blood Supply, Amsterdam) and suspended in Hank's balanced salt solution (HBSS) supplemented with 1\% gelatin. HEK-Blue hTLR4 cells were purchased from InvivoGen (San Diego, CA, USA), and were subcultured in DMEM high glucose supplemented with $10 \%(\mathrm{v} / \mathrm{v})$ fetal bovine serum, 2-4 mM L-glutamine, penicillin $(50 \mathrm{IU} / \mathrm{mL})$, streptomycin $(50 \mu \mathrm{g} / \mathrm{mL})$, and amphotericin $\mathrm{B}(0.25 \mu \mathrm{g} / \mathrm{mL})$, and incubated at $37^{\circ} \mathrm{C}$ under a $5 \%$ $\mathrm{CO}_{2}$ atmosphere.

\section{Liposome-uptake study}

RAW264.7 (40,000 cells) was seeded into each well of a $\mu$-Slide VI 0.4 IbiTreat Microscopy Chamber (Ibidi GmbH, Planegg, Germany) and incubated overnight. Cells were treated with $0.125 \mathrm{mM}$ TL of rhodamine-labeled $\omega$-liposomes or rhodamine-labeled C-liposomes for 4 hours at $37^{\circ} \mathrm{C}$. Afterward, cell nuclei were stained with Hoechst for 30 minutes, followed by thorough washing steps. Cells were visualized on a BZ-9000 fluorescence microscope (Keyence, Osaka, Japan) or on a confocal SPE-II microscope (Leica Microsystems, Wetzlar, Germany).

\section{Inhibition of production of reactive nitrogen species (NO assay)}

To evaluate the effect of liposomal formulations on the release of reactive nitrogen species, RAW264.7 cells were seeded at 100,000 cells per well in a 96-well plate. After 24 hours of incubation, cell-culture medium was removed from all wells and replaced with fresh medium spiked with the respective treatments - $\omega$-liposomes or C-liposomes - at the indicated concentrations. After 2 hours, lipopolysaccharide (LPS) was added at a final concentration of $100 \mathrm{ng} / \mathrm{mL}$, followed by incubation at $37^{\circ} \mathrm{C}$ for another 22 hours. In another setup, we evaluated the effect of $\omega$-liposomes or C-liposomes on RAW264.7 cells prestimulated with LPS. Briefly, we first stimulated RAW264.7 cells with LPS (100 ng/mL) for 2 or 4 hours, after which cells were washed with medium or not, and subsequently treated with the liposomes for another 22 hours. In either the pretreatment or the prestimulation setup, the supernatant was collected for a nitric oxide assay with Griess reagents. Absorbance was measured at $550 \mathrm{~nm}$ on a SpectroStar Nano (BMG LabTech, Ortenberg, Germany). The effect of liposome formulations on cell viability was assessed under similar conditions of the assay (ie, LPS stimulation, seeding density, and exposure time) to assure that the noticed antioxidant effects were not due to significant cytotoxic effects of the formulations. A CellTiter $96^{\circledR}$ Aqueous One solution viability assay (Promega Corporation, Fitchburg, WI, USA) was performed as per the supplier's protocol, and the absorbance was measured using EZ Read 400 (Biochrom, Cambridge, UK).

RAW264.7 NFאB Luc cells were seeded at 80,000 per well in a 96-well plate. After 24 hours of incubation, the medium was removed from all wells and replaced with either fresh medium or the respective $\omega$-liposomes or C-liposomes formulations at the indicated concentrations. This medium was removed and cells washed with fresh medium twice after 4 hours of treatment. Cells were stimulated with LPS at a final concentration of $100 \mathrm{ng} / \mathrm{mL}$ for 2 hours. Luciferase activity was determined using a One-Glo luciferase-assay system (Promega Corporation) according to the supplier's instructions. Cell viability was assessed under the same exposure time of LPS treatment and LPS stimulation as described earlier.

\section{Inhibition of production of proinflammatory cytokines TNF $\alpha$ and MCPI}

THP1 cells, a commonly used model for mimicking macrophages in the vasculature, ${ }^{21}$ were seeded at 250,000 cells per well in a 24-well plate and differentiated into macrophages as described earlier. The medium was replaced by a medium containing liposomal formulations for 2 hours, then stimulated with LPS for an additional 22 hours. The supernatant was collected and stored at $-80^{\circ} \mathrm{C}$ until further analysis. TNF $\alpha$ and MCP1 were measured by enzymelinked immunosorbent assay (ELISA) according to the manufacturer's instructions (ELISA Max $^{\mathrm{TM}}$ deluxe set human TNF $\alpha$ and human MCP1/CCL2 kits; BioLegend, San Diego, CA, US). Cell viability was determined as described earlier.

\section{Inhibition of production of reactive oxygen species (ROS assay)}

PMNs, freshly obtained from human buffy coat, were diluted to a final concentration of 250,000 cells $/ \mathrm{mL}$ and treated with $\omega$-liposomes and C-liposomes formulations at indicated concentrations in a white 96-well plate for 30 minutes. Subsequently, luminol, as luminescence enhancer, and zymosan, as reactive oxygen species (ROS) inducer, were pipetted into each well. The chemiluminescence resulting from ROS production was measured immediately using a Titertek Luminoskan (TechGen International, Zellik, Belgium). 
Inhibition of toll-like receptor 4 (TLR4) activation HEK-Blue hTLR 4 cells were seeded at 25,000 cells per well in a 96-well plate and treated with liposomes for 2 hours, followed by 16 hours of LPS stimulation. A Quanti-Blue assay (InvivoGen) was performed according to the manufacturer's instructions to determine the level of secreted alkaline phosphatase as a reporter for TLR4 activation. Cell viability was assessed as mentioned earlier.

\section{Experiments with cancer cell lines}

Murine 4T1 breast cancer cells and human FaDu squamous cell carcinoma cells were obtained from the ATCC. Cells were cultured in DMEM supplemented with $10 \%(\mathrm{v} / \mathrm{v})$ fetal bovine serum, penicillin $(100 \mathrm{IU} / \mathrm{mL})$, streptomycin $(100 \mu \mathrm{g} / \mathrm{mL})$, and amphotericin B $(0.25 \mu \mathrm{g} / \mathrm{mL})$. Normal human umbilical vein endothelial cells (HUVECs) were obtained from Lonza (Basel, Switzerland) and cultured in EBM basal medium supplemented with EGM-2 SingleQuot kit supplements and growth factors (Lonza).

FaDu squamous cell carcinoma cells or 4T1 metastatic breast cancer cells were seeded at a density of 3,000 cells per well in a 96-well plate. HUVECs, which served as control (normal cells), were seeded at a density of 4,000 cells per well in a 96-well plate. After 24 hours, cells were treated with $\omega$-liposomes and C-liposomes at the indicated concentrations for 24 hours. To determine the number of dividing cells, bromodeoxyuridine (BrdU) reagent was added to the cells for 4-6 hours and an ELISA BrdU colorimetric immunoassay (Hoffman-La Roche Ltd, Basel, Switzerland) was performed, according to the manufacturer's protocol.

\section{Statistical analysis}

Data are expressed as mean \pm standard error of mean. Statistical analyses by Student's $t$-test were performed with GraphPad Prism; values of $P<0.05$ were considered statistically significant.

\section{Results and discussion Preparation and characterization of $\omega$-liposomes}

The physicochemical characteristics of PUFA-loaded PEGylated liposomes ( $\omega$-liposomes) and control PEGylated liposomes (C-liposomes) are summarized in Table 1. Hydration of the lipid film with HBS resulted in a heterogeneous, milky dispersion for both $\omega$-liposomes and C-liposomes. The cumulative size distribution at $90 \%$ $\left(\mathrm{D}_{90}\right)$ of this lipid dispersion before extrusion was $2 \mu \mathrm{m}$ and $3 \mu \mathrm{m}$ for C-liposomes and $\omega$-liposomes, respectively (Figure S1A). After extrusion, both liposomal formulations were translucent and displayed comparable mean sizes (around $100 \mathrm{~nm}$ ), $\mathrm{D}_{90}$ (around $120 \mathrm{~nm}$ ), and narrow size distributions (polydispersity $<0.1$ ) (Table 1 and Figure S1B). The narrow size distribution is also demonstrated in the size-distribution histograms obtained from DLS (Figure S2). The slightly negative-close to neutral $\zeta$-potentials indicated that the negative charge of the DHA lipids was shielded by the PEG corona on the surface of liposomes (Table 1). TL recovery after extrusion was $69 \% \pm 8 \%$ and $70 \% \pm 10 \%$ for $\omega$-liposomes and C-liposomes, respectively, as determined by Rouser phosphate assay. The entrapment efficiency and DHA-loading content in $\omega$-liposomes were $81 \% \pm 3 \%$ and $15 \% \pm 1 \%$, respectively (Table 1). Separation of liposomes and free DHA by size-exclusion chromatography showed that DHA was effectively incorporated in the liposomes (Figure 2A). Changes in mean size and size distribution of both liposomal formulations were minimal under liposome-storage conditions at $4{ }^{\circ} \mathrm{C}$ over a period of 5 weeks (Figure 2B and C). Liposome-size distribution was relatively narrow and remained $<0.1$ on the PDI. In addition, there were no significant changes in particle size or PDI values between $\mathrm{C}$-liposomes and $\omega$-liposomes in a stability study at room temperature and $37^{\circ} \mathrm{C}$ at physiological $\mathrm{pH}$ (ie, $\mathrm{pH}$ 7.4) (Figure S3). Furthermore, differential scanning calorimetry showed no differences in the thermograms of the formulations, likely due to the stabilizing effect of cholesterol (Figure S4).

\section{Cell-uptake/interaction studies of liposomes}

Lipid-based nanocarriers can be efficiently internalized by phagocytic cells, and hence are an attractive system to deliver PUFAs to immune cells. Macrophages are known to be the most efficient in uptake of nanoparticles among the different cell types and may act as a reservoir for nanotherapeutics. ${ }^{13,22}$ Figure 3 shows that RAW264.7 macrophages internalized both $\omega$-liposomes and C-liposomes to a similar extent. Fluorescence microscopy was used to visualize the association and the uptake of rhodaminelabeled liposomes. We further utilized the power of confocal microcopy to visualize a focal intracellular plane, minimizing any extracellular signal. The accumulation of labeled liposomes in perinuclear vesicles suggests accumulation of either formulation in the endosomal/lysosomal compartment (Figure 3A-D). 

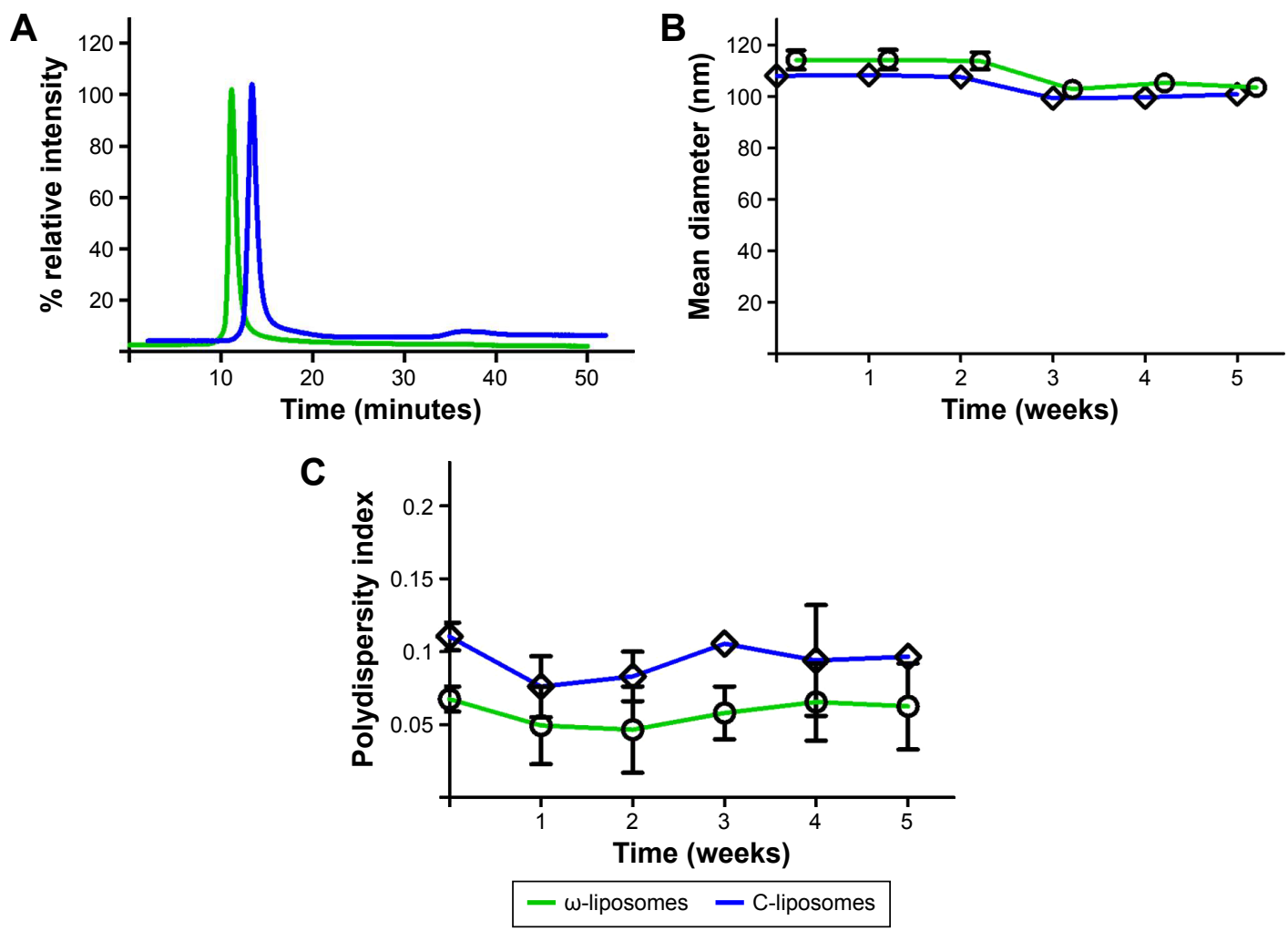

Figure 2 Purity and colloidal stability of docosahexaenoic acid (DHA)-loaded liposomes ( $\omega$-liposomes) and control liposomes (C-liposomes).

Notes: (A) Absence of free DHA in $\omega$-liposomes was confirmed by size-exclusion chromatography. (B and C) Colloidal stability of $\omega$-liposomes and C-liposomes were investigated by dynamic light scattering measuring the changes in (B) mean size and $(\mathbf{C})$ polydispersity index upon storage for over 30 days at $4^{\circ} \mathrm{C}$.

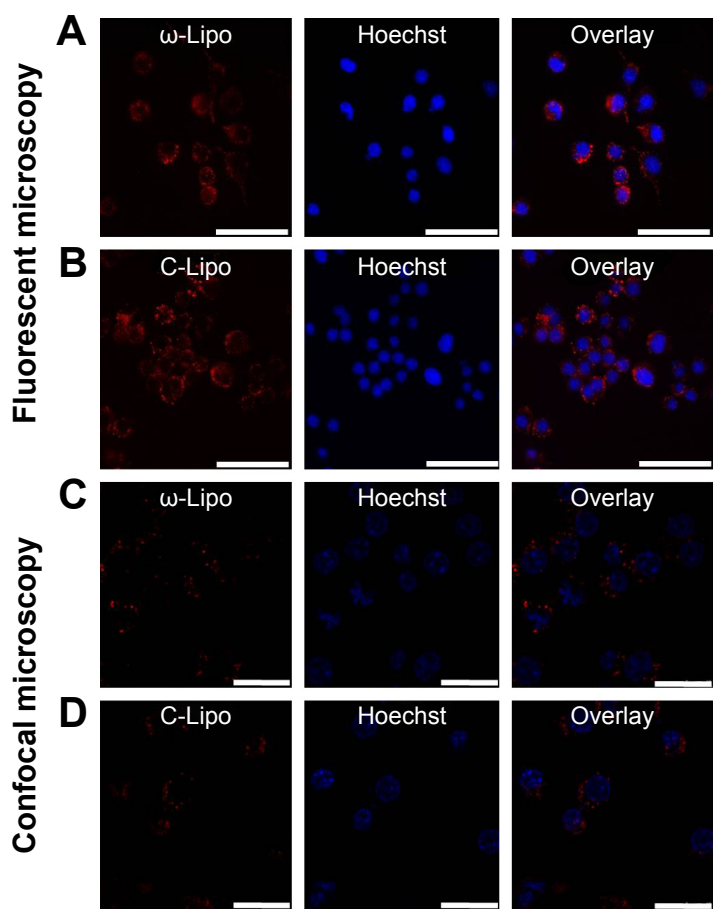

Figure 3 Cell-interaction and uptake studies of rhodamine-labeled docosahexaenoic acid-loaded liposomes ( $\omega$-Lipo) and control liposomes (C-Lipo) in RAW264.7 macrophages.

Notes: RAW264.7 murine macrophages were incubated for 4 hours at $37^{\circ} \mathrm{C}$ with rhodamine-labeled liposomes $(0.125 \mathrm{mM}$ total lipid; red). Cells were visualized with fluorescent microscopy (A and $\mathbf{B}$ ) or by confocal microscopy (C and $\mathbf{D})$. Blue staining represents cell nuclei. Scale bars $=20 \mu \mathrm{m}$.

\section{Effect of $\omega$-liposomes in activated immune cells}

Unbalanced reactive nitrogen species (RNS) and ROS are often generated by stimulated immune cells and play a crucial role in the development and progression of multiple inflammatory disorders. ${ }^{23-25}$ The effect of $\omega$-liposomes on the production of nitric oxide (NO) and ROS were evaluated in murine macrophages and human PMNs, respectively. NO is an important mediator in inflammation that reacts with superoxide to form peroxynitrite, a powerful oxidizing and tissue-damaging moiety. LPS induced a significant increase in NO production by RAW macrophages, and $\omega$-liposomes reduced LPS-induced NO production significantly, with up to $80 \%$ reduction at the highest tested concentration. Remarkably, C-liposomes also inhibited LPS-induced NO production by RAW cells dose-dependently, although less strongly than $\omega$-liposomes (50\% vs $80 \%$ at $0.5 \mathrm{mM}$ TL and $35 \%$ vs $60 \%$ at $0.25 \mathrm{mM}$ TL) (Figure 4A). In a different experimental setup in which cells had been prestimulated with LPS and then treated with liposomes, $\omega$-liposomes showed similar potent anti-inflammatory activity (Figure S5A-C). Since nuclear factor kappaB (NFkB) activation plays a crucial role in inducing NO production via inducible nitric oxide synthase, we 

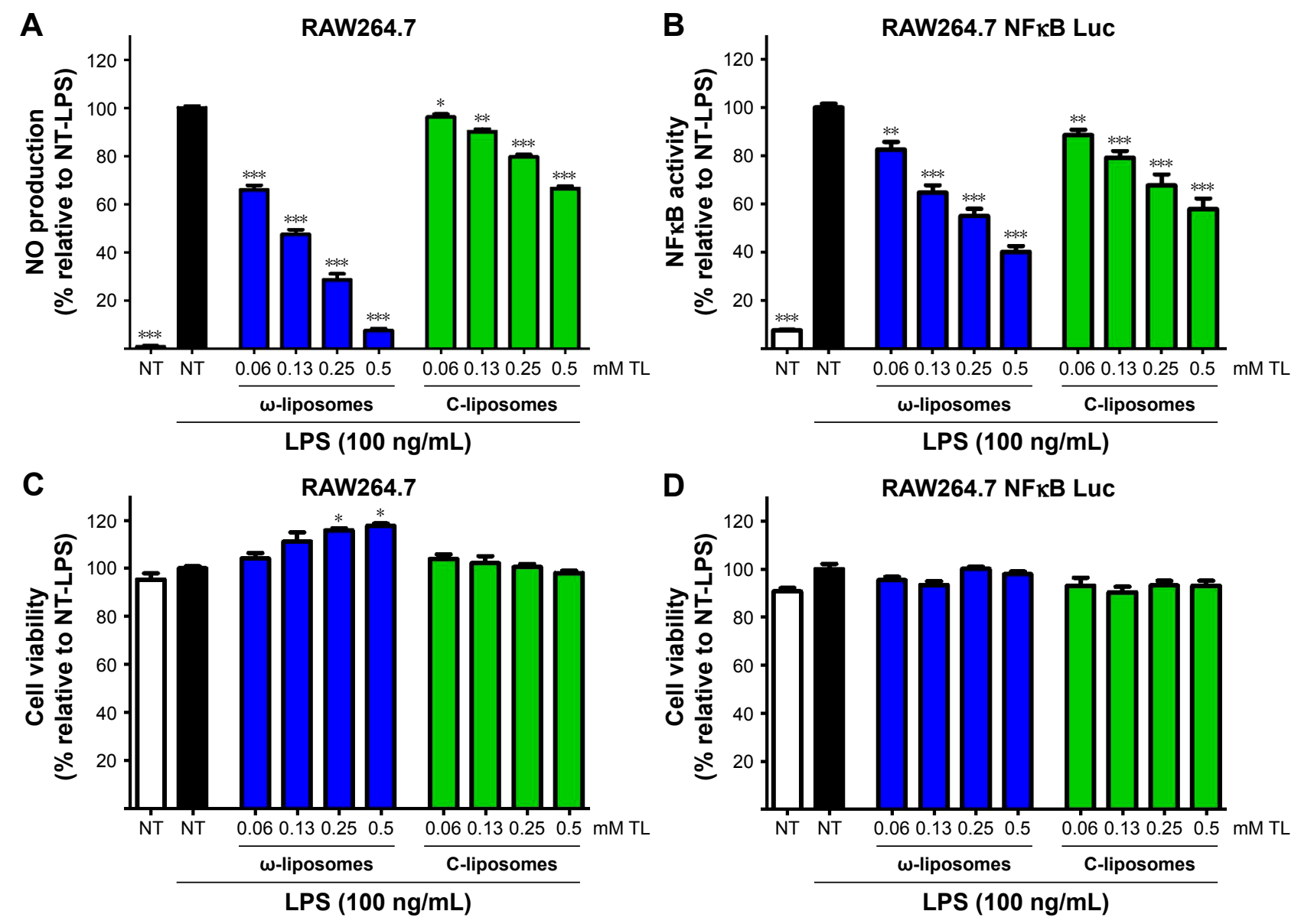

Figure 4 Effect of docosahexaenoic acid-loaded liposomes ( $\omega$-liposomes) and control liposomes (C-liposomes) on lipopolysaccharide (LPS)-induced nitric oxide production and NFKB activation in murine macrophages.

Notes: (A) RAW264.7 cells were treated with the liposomes and stimulated with LPS for 24 hours. NO production was measured in the supernatant with Griess reagent. (B) RAW264.7 NFKB Luc cells were treated with liposomes for 4 hours, washed twice with medium, then stimulated with LPS for another 2 hours. Luciferase activity was determined using the One-Glo luciferase assay. (C and D). Cell viability was assessed by MTS assay under the same experimental conditions. Data presented as mean \pm standard error of mean from three independent experiments (each $n \geq 4$ ). $* P<0.05, * * P<0.0$ I, $* * * P<0.00$ I compared to control nontreated (NT) LPS-stimulated cells (Student's $t$-test). White bars indicate nontreated, nonstimulated control cells; black bars indicate stimulated control cells not treated with liposomal formulations.

Abbreviations: Luc, luciferase; MTS, (3-(4,5-dimethylthiazol-2-yl)-5-(3-carboxymethoxyphenyl)-2-(4-sulfophenyl)-2H-tetrazolium); NO, nitric oxide; TL, total lipid.

sought to determine the effect of liposomes on RAW264.7 cells stably transfected with an NFkB-reporter gene, which expresses firefly luciferase upon activation. Both formulations showed inhibition of NFKB activation similarly to the observed inhibitory effects on NO production (Figure 4B). Of note, the liposomal formulations were not toxic to either of the cell lines at the tested concentration range and exposure time (Figure 4C and D).

The effects of $\omega$-liposomes on the production of two proinflammatory cytokines - MCP1 and TNF $\alpha$ - were also studied, as they are key regulators in the recruitment of immune cells to inflammatory lesions and exacerbation of the inflammation. ${ }^{26,27}$ THP1 macrophages were stimulated with LPS $(100 \mathrm{ng} / \mathrm{mL})$ and then treated with either $\omega$-liposomes or C-liposomes. $\omega$-Liposomes reduced the production of both cytokines, while C-liposomes had only minor effects (Figure 5A and B). The highest concentration of $\omega$-liposomes, $0.5 \mathrm{mM}$ TL, resulted in a minor reduction in THP1 cell viability of less than $30 \%$ compared to the untreated control cells (Figure 5C).

In addition to macrophages, neutrophils (PMNs) are a key source of ROS. ${ }^{28}$ Therefore, the effect of liposomes in an oxidative burst setup was assessed, where zymosan induced an increase in ROS production by neutrophils. ROS was remarkably reduced with $\omega$-liposome treatment by $60 \%$ and $90 \%$ at $0.06 \mathrm{mM}$ and $0.13 \mathrm{mM} \mathrm{TL}$, respectively. C-liposomes had no effect on zymosan-induced ROS production at any tested concentration (Figure 6).

The effects of $\omega$-liposomes were further examined on LPS-induced TLR4 activation. TLR4 is a key receptor recognizing damage-associated molecular patterns and pathogenassociated molecular patterns. As such, it plays a key role in atherosclerosis, cancer, and other chronic inflammatory diseases. ${ }^{29-32}$ Using HEK-blue TLR4 cells, the induction of 

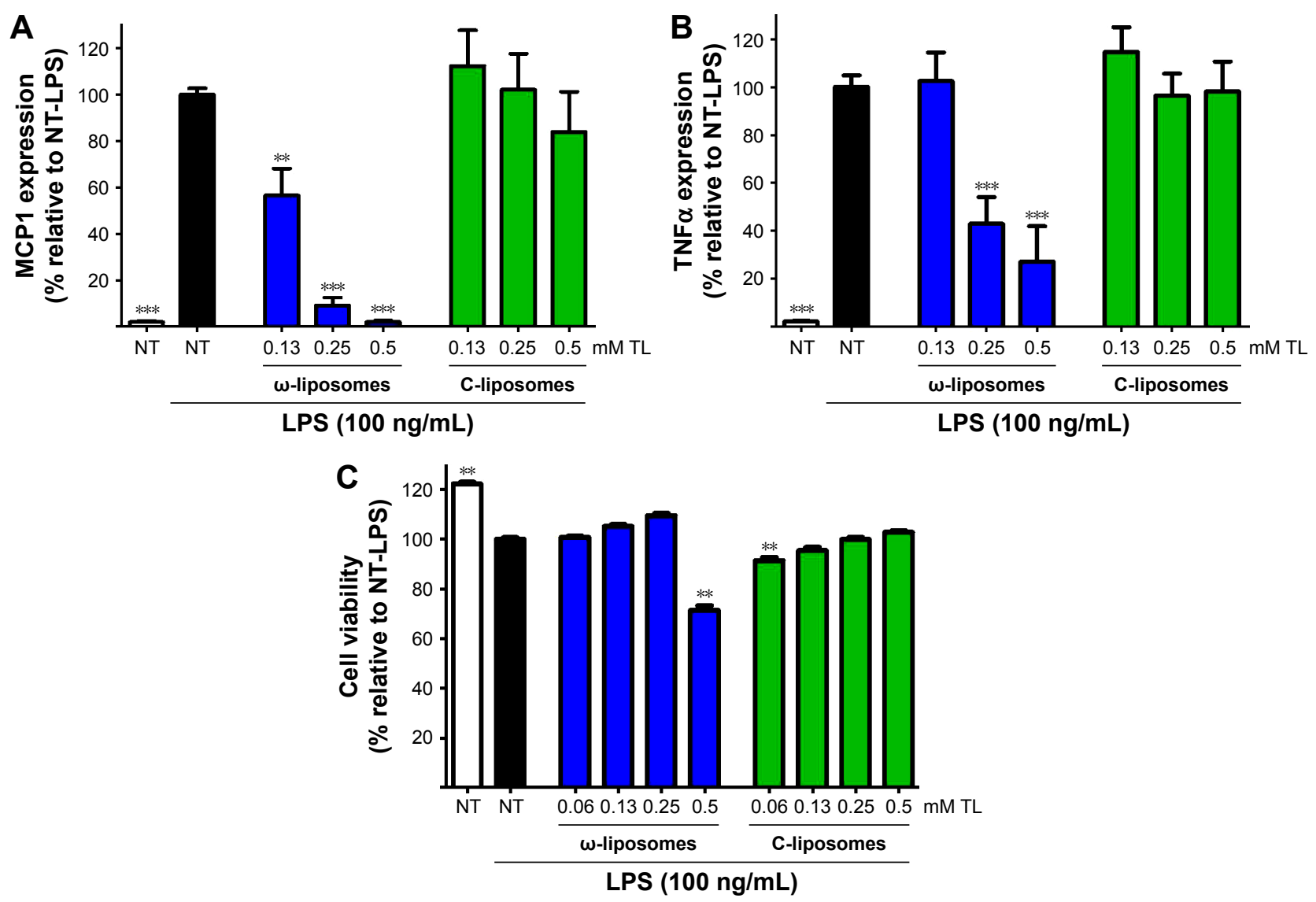

Figure 5 Effect of docosahexaenoic acid-loaded liposomes ( $\omega$-liposomes) and control liposomes (C-liposomes) on lipopolysaccharide (LPS)-induced proinflammatory cytokine production in macrophages.

Notes: Human THPI macrophages were treated with the liposomes and stimulated with LPS for 24 hours. (A) MCPI and (B) TNF $\alpha$ released in the supernatant were analyzed by enzyme-linked immunosorbent assay. Data presented as mean \pm standard deviation of one representative experiment performed in triplicate. (C) Cell viability was assessed by MTS assay under the same experimental conditions. $* * P<0.0$ I, $* * * P<0.00$ I compared to control nontreated (NT) LPS-stimulated cells (Student's $t$-test). White bars indicate nontreated, nonstimulated control cells; black bars indicate stimulated control cells not treated with liposomal formulations.

Abbreviation: TL, total lipid.

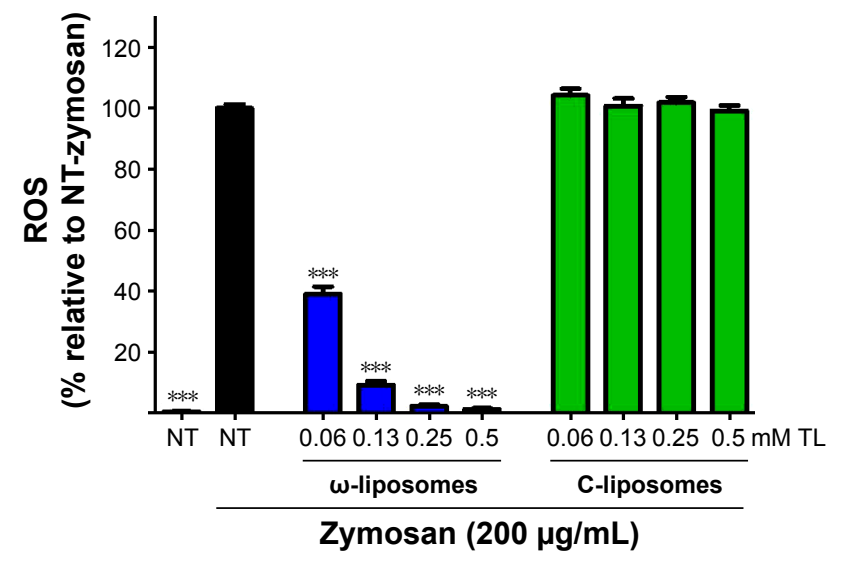

Figure 6 Effect of docosahexaenoic acid-loaded liposomes ( $\omega$-liposomes) and control liposomes (C-liposomes) on zymosan-induced neutrophil oxidative burst.

Notes: Polymorphonuclear neutrophils freshly isolated from a buffy coat were treated immediately with liposomes and stimulated with zymosan. Reactive oxygen species (ROS) generation was measured by using a luminol-amplified chemiluminescence assay. Data presented as mean \pm standard error of mean from one representative experiment performed in triplicate (each $n \geq 4$ ). $* * * P<0.00$ I compared to control nontreated (NT) zymosan-stimulated cells (Student's $t$-test). White bar indicates nontreated, nonstimulated control cells; black bar indicates stimulated control cells not treated with liposomal formulations.

Abbreviation: TL, total lipid.
TLR4-controlled expression of the reporter molecule secreted embryonic alkaline phosphatase (SEAP) was monitored. LPS triggered a fivefold increase in SEAP activity, which was reduced by $\omega$-liposomes in a dose-dependent manner, whereas C-liposomes had no effect (Figure 7A). $\omega$-Liposomes at $0.5 \mathrm{mM}$ TL (highest concentration) resulted in a minor reduction in cell viability of less than $30 \%$ compared to the untreated control cells (Figure 7B).

A number of studies have investigated the anti-inflammatory effects of PUFAs in general, and DHA specifically. These studies focused mainly on increasing the dietary intake of PUFAs, in in vivo and clinical studies, or by the use of DHA in its free form in vitro. ${ }^{3,5,31,33,34}$ DHA significantly decreased the expression of cytokine-induced leukocyte adhesionmolecule expression in human endothelial cells, while EPA, another member of PUFAs, did not. ${ }^{33}$ In a genomic study, Bouwens et al demonstrated that a high oral dose of DHA and EPA decreased the expression of genes involved in inflammatory pathways, such as eicosanoid synthesis, 

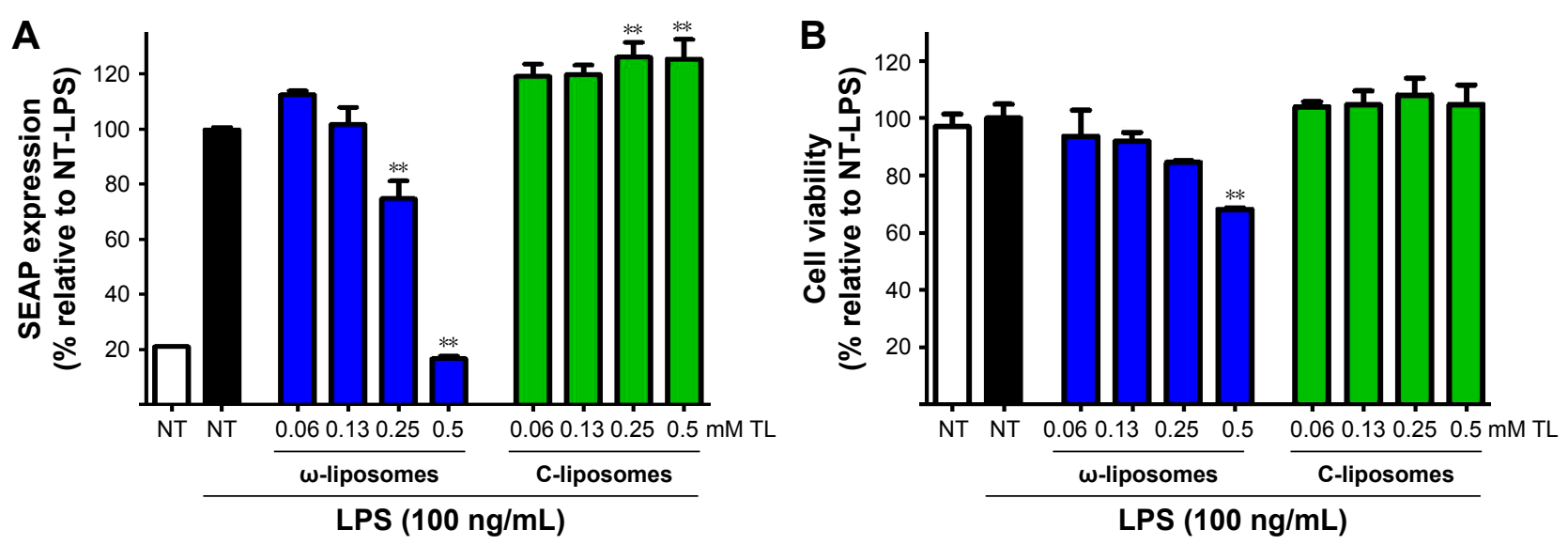

Figure 7 Effect of docosahexaenoic acid-loaded liposomes ( $\omega$-liposomes) and control liposomes (C-liposomes) on lipopolysaccharide (LPS)-induced TLR4 activation. Notes: Human HEK-Blue TLR4 cells were treated with the liposomes and stimulated with LPS for 18 hours. (A) TLR4 activation was monitored by measuring the secreted embryonic alkaline phosphatase (SEAP) in the medium calorimetrically. (B) Cell viability was assessed by MTS assay under the same experimental conditions. Data presented as mean \pm standard error of mean from two independent experiments (each $n \geq 4$ ). ${ }^{* * P}<0.0$ I compared to control nontreated (NT) LPS-stimulated cells (Student's $t$-test). White bars indicate nontreated, nonstimulated control cells; black bars indicate stimulated control cells not treated with liposomal formulations.

Abbreviation: TL, total lipid.

interleukin signaling, $\mathrm{NF \kappa B}$, and a decrease in oxidative stress and cell adhesion on the whole genome of peripheral blood mononuclear cells. ${ }^{12}$

\section{Effect of $\omega$-liposomes in cancer cell lines}

Aberrant cell proliferation is the hallmark of cancer and other chronic inflammatory diseases. Although targeting inflammation in cancer may reduce the invasive features of tumors, anti-inflammatory therapies are seen as adjunct therapy. ${ }^{35}$ Studies have demonstrated the effects of dietary PUFAs on the prevention and inhibition of cancers. ${ }^{2,4}$ Therefore, we investigated if $\omega$-liposomes could reduce aberrant cell proliferation. Bromodeoxyuridine (BrdU)-incorporation assays were performed, in which a thymidine analog incorporates only into the DNA of proliferating cells. $\omega$-Liposomes significantly reduced the proliferation of two fast-growing tumor models - human FaDu squamous carcinoma and murine 4T1 breast cancer - in vitro, while C-liposomes did not affect cell proliferation (Figure 8 ). $\omega$-Liposomes did not reduce the proliferation of control cells, as tested on normal HUVECs (Figure S6).

The exact mechanisms of action of PUFAs in general and DHA specifically are not well known. Possibly, the incorporation of PUFAs into the cell membrane may affect membrane
A

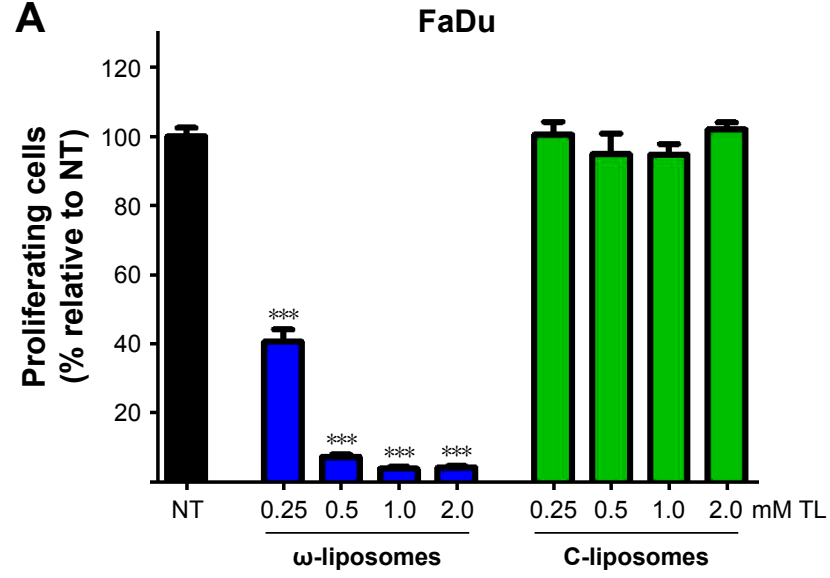

B

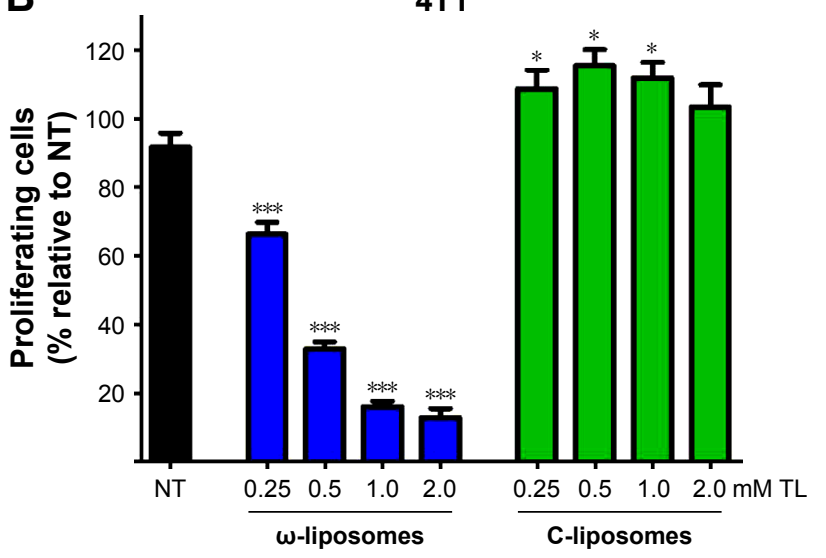

Figure 8 Effect of docosahexaenoic acid-loaded liposomes ( $\omega$-liposomes) and control liposomes (C-liposomes) on tumor-cell proliferation.

Notes: (A) FaDu cells and (B) 4TI cells were exposed for 24 hours to $\omega$-liposomes and C-liposomes, after which the medium was replaced with medium containing bromodeoxyuridine (BrdU) and cells incubated for additional 4-6 hours. Afterward, BrdU incorporation was determined by enzyme-linked immunosorbent assay. Data presented as mean \pm standard error of mean from three independent experiments (each $n \geq 4$ ). $* P<0.05$, **** $<0.00$ I compared to control nontreated (NT) cells (Student's $t$-test).

Abbreviation: TL, total lipid. 
fluidity, ligand recognition, and downstream signalling. ${ }^{36}$ Furthermore, GPR120, a novel G-protein-coupled receptor, was identified as a sensor for PUFAs. ${ }^{37}$ Also, PUFAs may act as precursors for specialized lipid mediators, such as resolvins and protectins, which possess potent anti-inflammatory effects and assist in the resolution of inflammation. ${ }^{38}$

In this study, a simple nanonutraceutical-based strategy was adopted to deliver effective doses of PUFAs, which dampen the inflammatory phenotype of inflammatory immune cells involved in chronic inflammation. Their antiproliferative activities against cancer cells were also demonstrated. The developed $\omega$-liposomes possess several advantages over the classical dietary intake of DHA, which requires a long duration of intake at high doses. First, formulation into liposomes allows the solubilization of DHA in aqueous solutions at high concentrations, which is required for injection in a low volume. Next, PEGylated liposomes circulate longer and accumulate to a higher extent in inflamed tissues.

Most nanoparticles for in vivo use, which have particle size of 10-300 nm, nonspecifically accumulate in the reticuloendothelial system (RES), eg, in the liver and spleen, and other tissues. Nanoparticles are also however accumulated in pathological lesions by the EPR effect, as demonstrated for atherosclerotic plaques, inflamed joints in rheumatoid arthritis, and tumors. Such lesions are rich in immune cells, mainly macrophages, which drive the pathophysiological inflammation and contribute to the leaky vasculature. ${ }^{13,15,16}$ These macrophages have the highest uptake activity compared to other professional phagocytes and other cells. ${ }^{13}$ PEGylation will prolong the circulation time of liposomes, and hence increases the chance for extravasation by EPR to the inflamed tissue.

Therefore, this approach can improve the pharmacokinetic profile of DHA and will boost its activities. Of note, a clinically approved total parenteral nutrition (eg, Omegaven), which is rich in DHA and EPA, is prescribed at a dose up to $2.5 \mathrm{~g} /$ day for 4 weeks to reduce risks of liver damage. ${ }^{39} \mathrm{Such}$ non-PEGylated emulsion is cleared more quickly (half-life 54 minutes, as described in the manufacturer's manual) when compared to long-circulating PEGylated liposomes, such as Doxil (half-life 20-30 hours), ${ }^{40}$ and hence will have less chance to accumulate in inflamed tissues by EPR extravasation. In addition to the longer circulation, liposomes can improve the chemical stability of DHA, which is susceptible to fast oxidation. ${ }^{41-43}$ Moreover, $\omega$-liposomes are a tunable drug-delivery platform in which other drugs can be loaded into the liposomal aqueous core, for synergism, or a targeting ligand can be attached to the surface, for an active targeting approach toward specific cell types. ${ }^{44}$

\section{Conclusion}

DHA was successfully incorporated in long-circulating PEGylated liposomes to form $\omega$-liposomes. The formulation remained stable and active upon storage over a month. Furthermore, $\omega$-liposomes possess strong antioxidant and anti-inflammatory effects in vitro, as demonstrated by the inhibition of the production of ROS, NO, MCP1, and TNF $\alpha$, and the inhibition of NFKB activation, in activated immune cells. They also induce strong inhibition of tumor-cell proliferation. This nanonutraceutical represents a nanomedicine-based approach for delivery of relatively safe nutraceutical components that can be applied for the prevention or management of chronic inflammatory diseases and cancer.

\section{Acknowledgment}

This work was supported by the European Framework Program 7 grant FP7-Health 309820: Nano-Athero.

\section{Disclosure}

The authors report no conflicts of interest in this work.

\section{References}

1. Yoshihara T, Shimada K, Fukao K, et al. Omega 3 polyunsaturated fatty acids suppress the development of aortic aneurysms through the inhibition of macrophage-mediated inflammation. Circ J. 2015;79(7): 1470-1478.

2. Barnés CM, Prox D, Christison-Lagay EA, et al. Inhibition of neuroblastoma cell proliferation with omega-3 fatty acids and treatment of a murine model of human neuroblastoma using a diet enriched with omega-3 fatty acids in combination with sunitinib. Pediatr Res. 2012;71(2): $168-178$.

3. Saravanan P, Davidson NC, Schmidt EB, Calder PC. Cardiovascular effects of marine omega-3 fatty acids. Lancet. 2010;376(9740): $540-550$.

4. Terry P, Lichtenstein P, Feychting M, Ahlbom A, Wolk A. Fatty fish consumption and risk of prostate cancer. Lancet. 2001;357(9270): $1764-1766$.

5. Calder PC. Long-chain fatty acids and inflammation. Proc Nutr Soc. 2012; 71(2):284-289.

6. Pittet MJ, Swirski FK. Monocytes link atherosclerosis and cancer. Eur J Immunol. 2011;41(9):2519-2522.

7. Li Q, Withoff S, Verma IM. Inflammation-associated cancer: NF-кB is the lynchpin. Trends Immunol. 2005;26(6):318-325.

8. Richard D, Kefi K, Barbe U, Bausero P, Visioli F. Polyunsaturated fatty acids as antioxidants. Pharmacol Res. 2008;57(6):451-455.

9. Ross JS, Stagliano NE, Donovan MJ, Breitbart RE, Ginsburg GS. Atherosclerosis and cancer: common molecular pathways of disease development and progression. Ann N Y Acad Sci. 2001;947:271-293.

10. Schmidt EB, Varming K, Pedersen JO, et al. Long-term supplementation with n-3 fatty acids, II: effect on neutrophil and monocyte chemotaxis. Scand J Clin Lab Invest. 1992;52(3):229-236.

11. Geusens P, Wouters C, Nijs J, Jiang Y, Dequeker J. Long-term effect of omega-3 fatty acid supplementation in active rheumatoid arthritis: a 12-month, double-blind, controlled study. Arthritis Rheum. 1994;37(6): 824-829.

12. Bouwens M, van de Rest O, Dellschaft N, et al. Fish-oil supplementation induces antiinflammatory gene expression profiles in human blood mononuclear cells. Am J Clin Nutr. 2009;90(2):415-424. 
13. Weissleder R, Nahrendorf M, Pittet MJ. Imaging macrophages with nanoparticles. Nat Mater. 2014;13(2):125-138.

14. Maeda H, Wu J, Sawa T, Matsumura Y, Hori K. Tumor vascular permeability and the EPR effect in macromolecular therapeutics: a review. $J$ Control Release. 2000;65(1-2):271-284.

15. van den Hoven JM, Van Tomme SR, Metselaar JM, Nuijen B, Beijnen JH, Storm G. Liposomal drug formulations in the treatment of rheumatoid arthritis. Mol Pharm. 2011;8(4):1002-1015.

16. Lobatto ME, Calcagno C, Millon A, et al. Atherosclerotic plaque targeting mechanism of long-circulating nanoparticles established by multimodal imaging. ACS Nano. 2015;9(2):1837-1847.

17. Allen TM, Cullis PR. Liposomal drug delivery systems: from concept to clinical applications. Adv Drug Deliv Rev. 2013;65(1):36-48.

18. Lammers T, Kiessling F, Hennink WE, Storm G. Drug targeting to tumors: principles, pitfalls and (pre-) clinical progress. J Control Release. 2012;161(2):175-187.

19. Eckert GP, Chang S, Eckmann J, et al. Liposome-incorporated DHA increases neuronal survival by enhancing non-amyloidogenic APP processing. Biochim Biophys Acta. 2011;1808(1):236-243.

20. Rouser G, Fkeischer S, Yamamoto A. Two dimensional then layer chromatographic separation of polar lipids and determination of phospholipids by phosphorus analysis of spots. Lipids. 1970;5(5):494-496.

21. Qin Z. The use of THP-1 cells as a model for mimicking the function and regulation of monocytes and macrophages in the vasculature Atherosclerosis. 2012;221(1):2-11.

22. Miller MA, Zheng YR, Gadde S, et al. Tumour-associated macrophages act as a slow-release reservoir of nano-therapeutic Pt(IV) pro-drug. Nat Commun. 2015;6:8692.

23. Franco R, Schoneveld O, Georgakilas AG, Panayiotidis MI. Oxidative stress, DNA methylation and carcinogenesis. Cancer Lett. 2008; 266(1):6-11.

24. Reuter S, Gupta SC, Chaturvedi MM, Aggarwal BB. Oxidative stress, inflammation, and cancer: how are they linked? Free Radic Biol Med. 2010;49(11):1603-1616.

25. Li H, Horke S, Förstermann U. Vascular oxidative stress, nitric oxide and atherosclerosis. Atherosclerosis. 2014;237(1):208-219.

26. Kalliolias GD, Ivashkiv LB. TNF biology, pathogenic mechanisms and emerging therapeutic strategies. Nat Rev Rheumatol. 2016;12(1) 49-62.

27. Deshmane SL, Kremlev S, Amini S, Sawaya BE. Monocyte chemoattractant protein-1 (MCP-1): an overview. J Interferon Cytokine Res. 2009;29(6):313-326.

28. Wright HL, Moots RJ, Bucknall RC, Edwards SW. Neutrophil function in inflammation and inflammatory diseases. Rheumatology (Oxford). 2010;49(9):1618-1631.

29. Brand K, Page S, Rogler G, et al. Activated transcription factor nuclear factor-kappa B is present in the atherosclerotic lesion. $J$ Clin Invest. 1996;97(7):1715-1722.

30. Pikarsky E, Porat RM, Stein I, et al. NF- $\mathrm{KB}$ functions as a tumour promoter in inflammation-associated cancer. Nature. 2004;431(7007): $461-466$.
31. Li H, Ruan XZ, Powis SH, et al. EPA and DHA reduce LPS-induced inflammation responses in HK-2 cells: evidence for a PPAR- $\gamma$-dependent mechanism. Kidney Int. 2005;67(3):867-874.

32. Wong SW, Kwon MJ, Choi AM, Kim HP, Nakahira K, Hwang DH. Fatty acids modulate Toll-like receptor 4 activation through regulation of receptor dimerization and recruitment into lipid rafts in a reactive oxygen species-dependent manner. J Biol Chem. 2009;284(40): 27384-27392.

33. De Caterina R, Cybulsky MI, Clinton SK, Gimbrone MA Jr, Libby P. The omega-3 fatty acid docosahexaenoate reduces cytokine-induced expression of proatherogenic and proinflammatory proteins in human endothelial cells. Arterioscler Thromb. 1994;14(11):1829-1836.

34. Rahman MM, Veigas JM, Williams PJ, Fernandes G. DHA is a more potent inhibitor of breast cancer metastasis to bone and related osteolysis than EPA. Breast Cancer Res Treat. 2013;141(3):341-352.

35. Rayburn ER, Ezell SJ, Zhang R. Anti-inflammatory agents for cancer therapy. Mol Cell Pharmacol. 2009;1(1):29-43.

36. Ma DW, Seo J, Davidson LA, et al. n-3 PUFA alter caveolae lipid composition and resident protein localization in mouse colon. FASEB J. 2004;18(9):1040-1042.

37. Oh DY, Talukdar S, Bae EJ, et al. GPR120 is an omega-3 fatty acid receptor mediating potent anti-inflammatory and insulin-sensitizing effects. Cell. 2010;142(5):687-698.

38. Kalish BT, Le HD, Fitzgerald JM, et al. Intravenous fish oil lipid emulsion promotes a shift toward anti-inflammatory proresolving lipid mediators. Am J Physiol Gastrointest Liver Physiol. 2013;305(11):G818-G828.

39. Park KT, Nespor C, Kerner J Jr. The use of Omegaven in treating parenteral nutrition-associated liver disease. J Perinatol. 2011;31 Suppl 1: S57-S60.

40. Gabizon A, Shmeeda H, Barenholz Y. Pharmacokinetics of PEGylated liposomal doxorubicin: review of animal and human studies. Clin Pharmacokinet. 2003;42(5):419-436.

41. Song JH, Inoue Y, Miyazawa T. Oxidative stability of docosahexaenoic acid-containing oils in the form of phospholipids, triacylglycerols, and ethyl esters. Biosci Biotechnol Biochem. 1997;61(12):2085-2088.

42. Kubo K, Sekine S, Saito M. Docosahexaenoic acid-containing phosphatidylethanolamine in the external layer of liposomes protects docosahexaenoic acid from 2,2'-azobis(2-aminopropane) dihydrochloride-mediated lipid peroxidation. Arch Biochem Biophys. 2003;410(1):141-148.

43. Lu FS, Nielsen NS, Timm-Heinrich M, Jacobsen C. Oxidative stability of marine phospholipids in the liposomal form and their applications. Lipids. 2011;46(1):3-23.

44. van der Meel R, Oliveira S, Altintas I, et al. Inhibition of tumor growth by targeted anti-EGFR/IGF-1R nanobullets depends on efficient blocking of cell survival pathways. Mol Pharm. 2013;10(10): 3717-3727. 


\section{Supplementary materials}

A
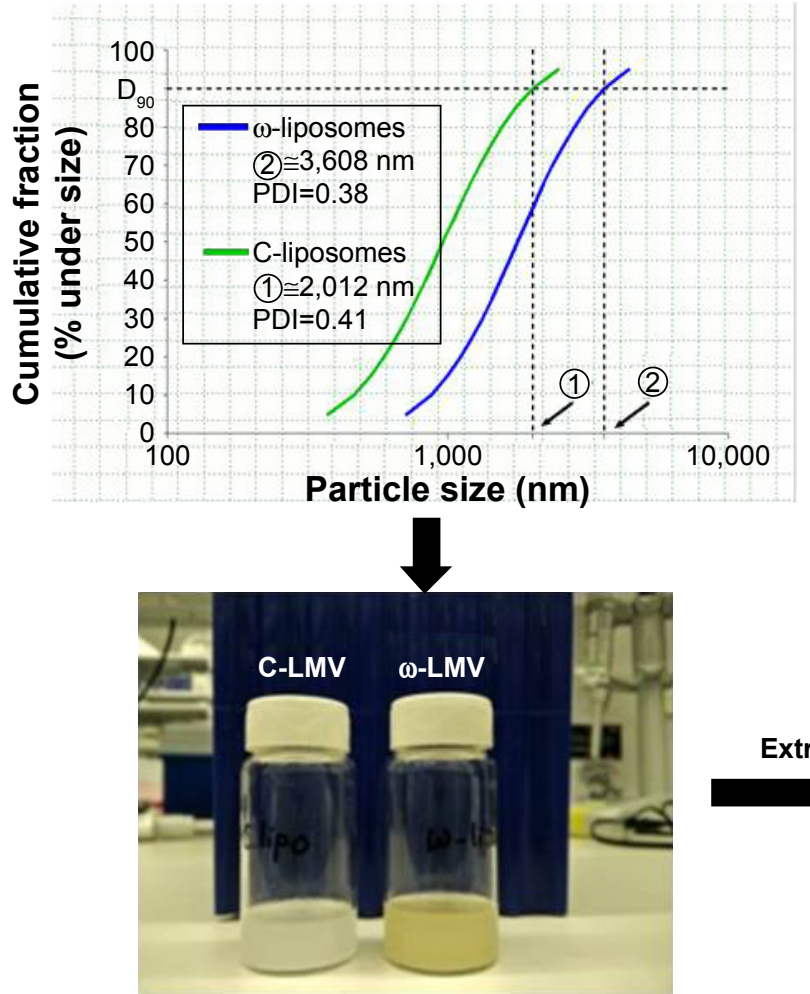

B

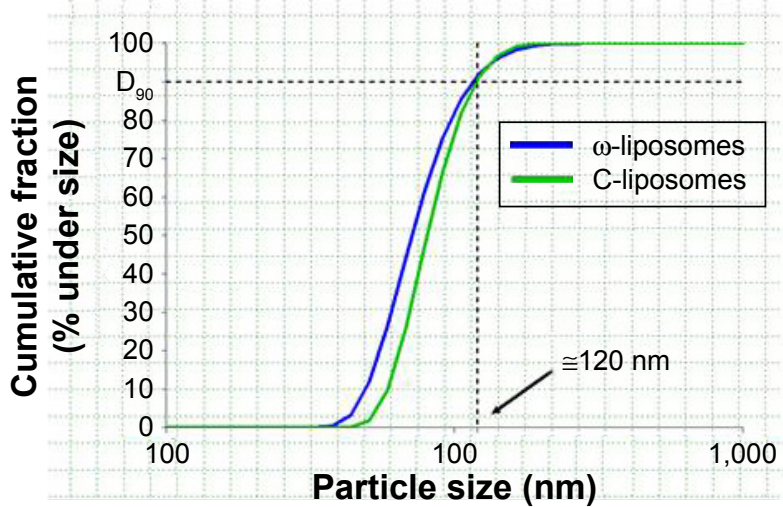

Extrusion

gure SI Physical appearance and calculation of $D_{90}$ of $\omega$-liposomes and control liposomes (C-liposomes) before $(\mathbf{A})$ and after $(\mathbf{B})$ extrusion

Abbreviations: C-LMV, control large, multilamellar vesicles; $\mathrm{D}_{90}$, size distribution at $90 \%$; PDI, polydispersity index; $\omega$-liposomes, docosahexaenoic acid-loaded liposomes; $\omega$-LMV, docosahexaenoic acid-loaded large, multilamellar vesicles.

A

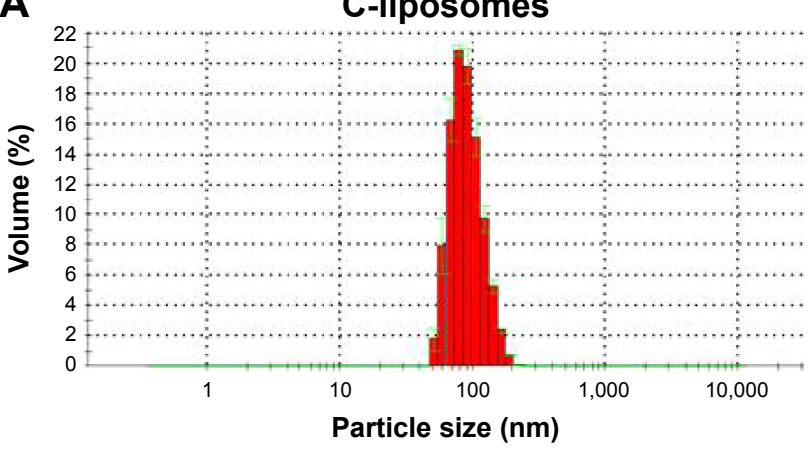

B

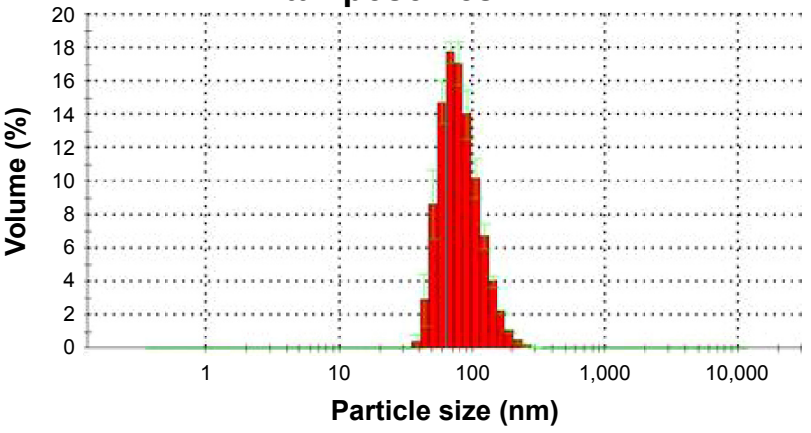

Figure S2 Dynamic light scattering-generated histograms demonstrating the particle-size distribution of $\omega$-liposomes (B) and control liposomes (C-liposomes) (A) after extrusion.

Abbreviation: $\omega$-liposomes, docosahexaenoic acid-loaded liposomes. 

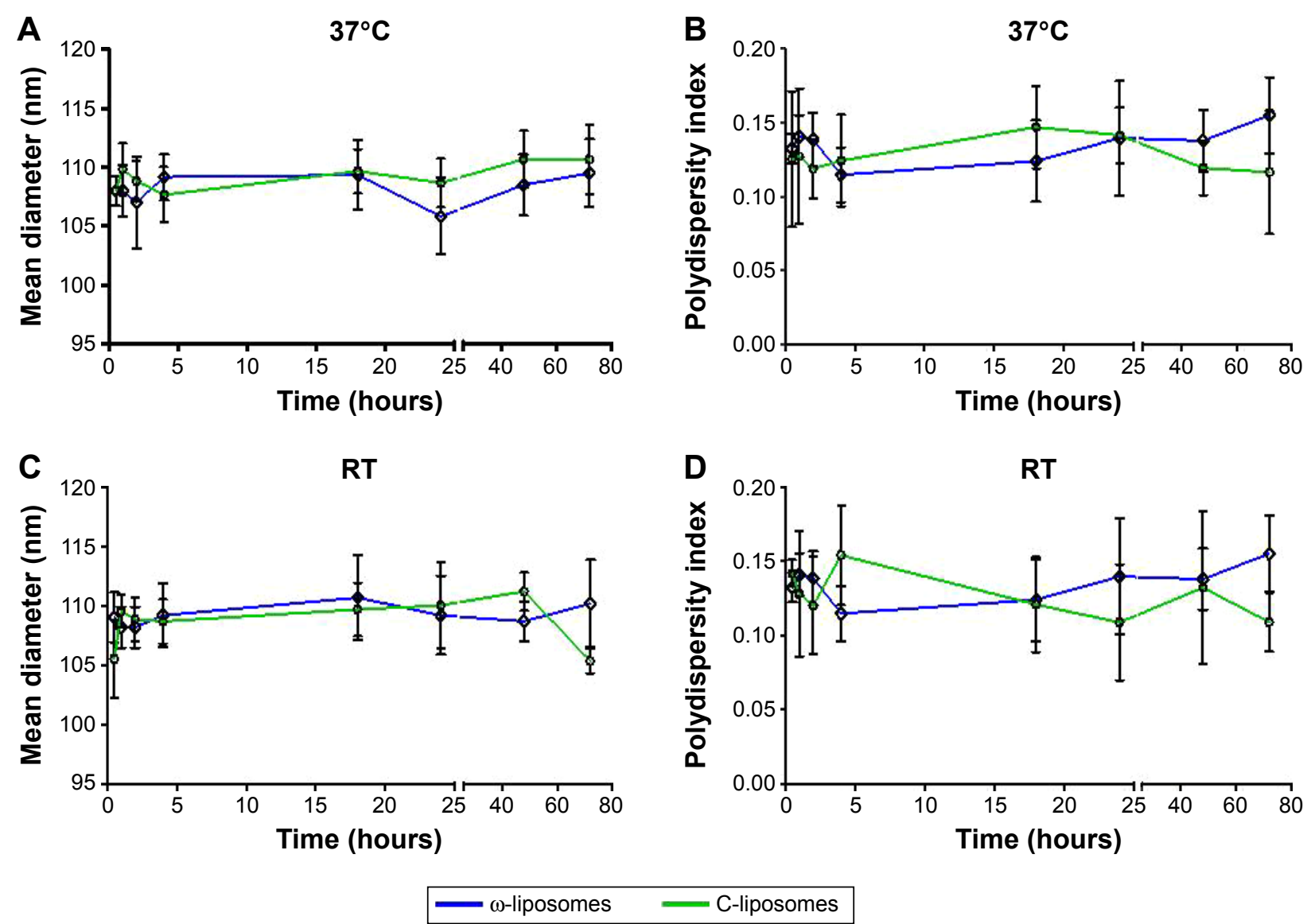

Figure S3 Colloidal stability of $\omega$-liposomes and control liposomes (C-liposomes) at room temperature (RT) and $37^{\circ} \mathrm{C}$.

Note: Particle size (A and $\mathbf{C}$ ) and polydispersity index (B and $\mathbf{D})$ were monitored with dynamic light scattering over 72 hours. Abbreviation: $\omega$-liposomes, docosahexaenoic acid-loaded liposomes.



Figure S4 Thermotropic stability of liposomes.

Notes: The thermotropic stability of the liposomes was analyzed using discovery differential scanning calorimetry and HEPES buffered saline as reference. The thermal behavior of the liposomes was monitored between $4^{\circ} \mathrm{C}$ and $60^{\circ} \mathrm{C}$, with increasing steps of $0.5^{\circ} \mathrm{C}$ per minute.

Abbreviations: C-liposomes, control liposomes; HEPES, 4-(2-hydroxyethyl)-I-piperazineethanesulfonic acid; $\omega$-liposomes, docosahexaenoic acid-loaded liposomes. 
A

2 hours LPS +22 hours T

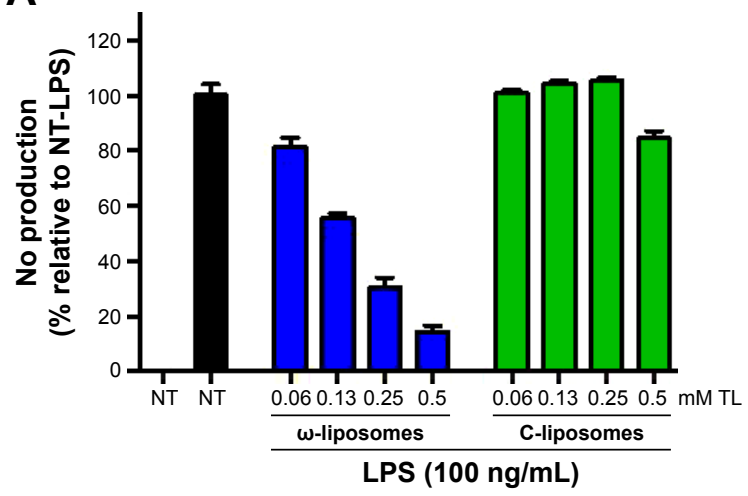

B

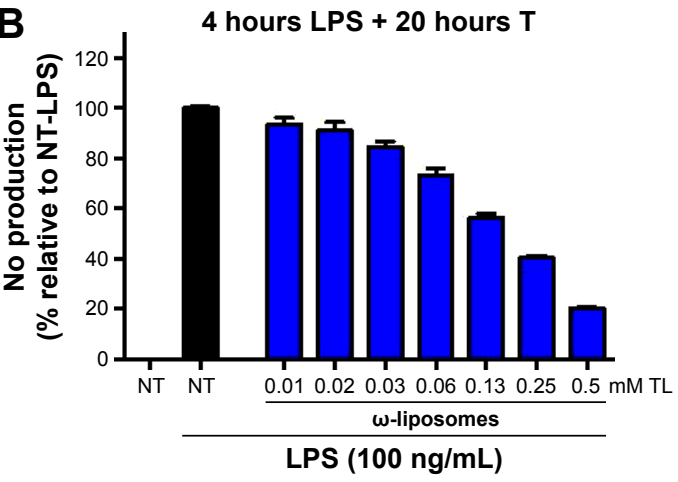

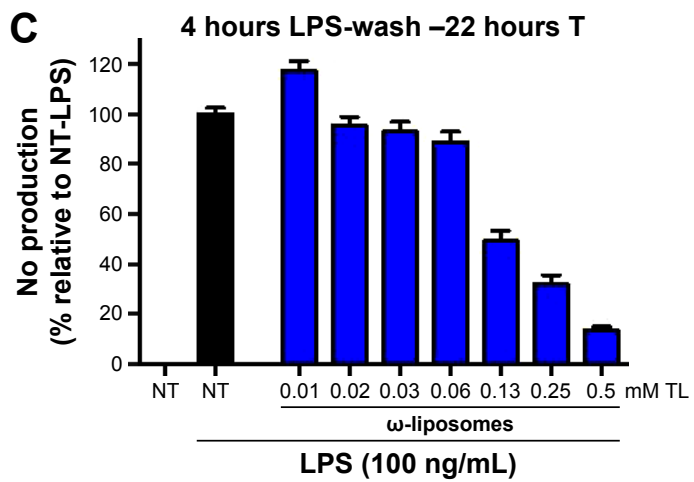

Figure S5 Effect of $\omega$-liposomes and control liposomes (C-liposomes) on lipopolysaccharide (LPS)-induced nitric oxide production in prestimulated murine macrophages. Notes: (A) RAW264.7 cells were stimulated with LPS for 2 or 4 hours (B, C). Afterward, LPS was washed $(\mathbf{C})$ or not $(\mathbf{A}$ and $\mathbf{B})$, and cells were treated with $\omega$-liposomes or $\mathrm{C}$-liposomes. NO production was measured in the supernatant with Griess reagent. Data presented as mean \pm standard error of mean from a representative experiment $(\mathrm{n}=4)$. Abbreviations: NT, nontreated; TL, total lipid; $\omega$-liposomes, docosahexaenoic acid-loaded liposomes.

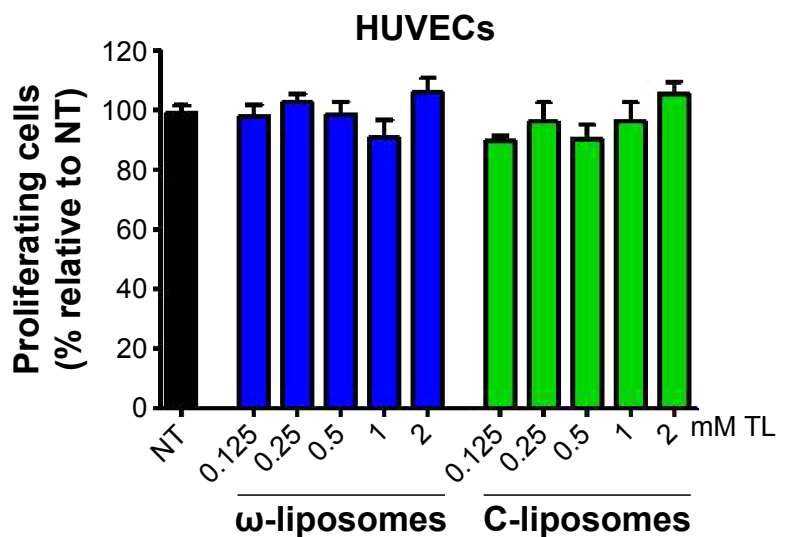

Figure S6 Effect of $\omega$-liposomes and control liposomes (C-liposomes) on proliferation of human umbilical vein endothelial cells (HUVECs).

Notes: HUVECs were seeded at 4,000 cells/well in a 96-well plate. Cells were exposed for 24 hours to $\omega$-liposomes and C-liposomes, after which the medium was replaced with medium containing bromodeoxyuridine ( $\mathrm{BrdU})$ and cells incubated for an additional 4-6 hours. Afterward, BrdU incorporation was determined by enzyme-linked immunosorbent assay. Data presented as mean \pm standard error of mean from a representative experiment $(n=6)$.

Abbreviations: NT, nontreated; TL, total lipid; $\omega$-liposomes, docosahexaenoic acid-loaded liposomes.

\section{Publish your work in this journal}

The International Journal of Nanomedicine is an international, peerreviewed journal focusing on the application of nanotechnology in diagnostics, therapeutics, and drug delivery systems throughout the biomedical field. This journal is indexed on PubMed Central, MedLine, CAS, SciSearch ${ }^{\circledR}$, Current Contents ${ }^{\circledR} /$ Clinical Medicine,
Journal Citation Reports/Science Edition, EMBase, Scopus and the Elsevier Bibliographic databases. The manuscript management system is completely online and includes a very quick and fair peer-review system, which is all easy to use. Visit http://www.dovepress.com/ testimonials.php to read real quotes from published authors. 